\title{
Correction to: Seasonal variation in reef fish assemblages in the environmentally extreme southern Persian/Arabian Gulf
}

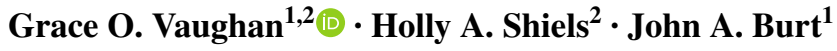

Published online: 13 January 2021

(C) Springer-Verlag GmbH Germany, part of Springer Nature 2021

\section{Correction to:}

Coral Reefs

https://doi.org/10.1007/s00338-020-02041-2

reef fish behaviour in the Arabian/Persian Gulf. Coral Reef 39, 733-744 (2020). https://doi.org/10.1007/ s00338-019-01847-z.

The original article has been corrected.

This erratum is published as citation for article in the reference list needs to be read as:

D'Agostino D, Chapman B, Burt JA, Reader T, Grace O. Vaughan, Santinelli V, Cavalcante G and Feary DA (2019) The influence of thermal extremes on coral

Publisher's Note Springer Nature remains neutral with regard to jurisdictional claims in published maps and institutional affiliations.

The original article can be found online at https://doi.org/10. 1007/s00338-020-02041-2.

Grace O. Vaughan

grace.vaughan@nyu.edu

1 Center for Genomics and Systems Biology, New York

University Abu Dhabi, PO Box 129188, Abu Dhabi,

United Arab Emirates

2 Faculty of Biology, Medicine and Health, The University of Manchester, 3.15d Core Technology Facility, Manchester, UK 